\title{
Comentários. Um sonho desconcertante ${ }^{1}$
}

\author{
Marlene Rozenberg ${ }^{2}$
}

Temos dois textos complexos, profundos e desconcertantes. Lendo os dois textos fui percebendo que há pontos em comum, com usos de modelos diferentes. Usando o texto de Mariano para entender meu desconcerto diante da tarefa, penso que passei pelas três formas de escuta a que ele se refere: enigma, mistério e desconcerto. A primeira sensação é que tinha enigmas para decifrar. Tanto que depois de ler, tive um sonho: andava pela Av. Paulista e recebi um bilhete de uma pessoa que me dizia: se você não decifrar, você vai ser vítima do que o enigma propõe. Estava diante da esfinge como Édipo. No assalto do sonho, a angústia era enorme, e não achava a resposta. Estava diante do desafio de uma decifração. Quando acordei, relacionei a minha responsabilidade de comentadora dos dois textos, de dois colegas que aprecio muito. E vi que a decifração seria eu mesma escrevendo e me apresentando. O sonho me desconcertou, mas me possibilitou pensar. Será que os sonhos são sempre desconcertantes? Em sua maioria nos surpreendem. Neste estado de surpresa me debrucei nos textos para poder sonhá-los e fui tentando, sob a forma de detetive de mistérios, ler nas entrelinhas e me envolver no conteúdo, feito um meteco (estrangeiro), me misturando, mas, ao mesmo tempo, me alheando para poder ouvir melhor os autores. Ser contemporânea, como foi definido, aderindo e me diferenciando. E fui me identificando, como analista e como leitora, assim podendo me transformar num detetive selvagem de ambos os textos, ou seja, me manter em estado de desconcerto fértil e criativo a partir das surpresas que fui vivenciando. Travessia, movimento, cesura. Penso que a criatividade tem sempre um fator de surpresa e espanto implicados. Criar é romper e a primeira sensação é de um espaço vazio e espera ativa para que surja

\footnotetext{
${ }^{1}$ Este trabalho foi apresentado em oficina sobre as plenárias no I Simpósio Bienal "O mesmo, o outro: Psicanálise em movimento" eixo "O analista desconcertado: mal estar e cínica" da Sociedade Brasileira de Psicanálise de São Paulo.

${ }^{2}$ Membro efetivo e analista didata, coordenadora de seminários clínicos e teóricos do Instituto de Psicanálise da SBPSP
} 
uma nova composição. Para Winnicott (1971/1975), a criatividade é fundamento para o surgimento da subjetividade que depende da hospitalidade do outro para dar lugar à sua singularidade. Destaca a importância do ambiente externo para se criar o espaço potencial. Sem este a singularidade do indivíduo não ganha morada. Seria esse espaço potencialmente desconcertante? O processo de ilusão encobre este desconcerto? E a vida cultural uma maneira de lidar com este desconcerto? Podemos pensar aqui o desconcerto como vivências de rupturas, desilusões, que podem gerar crescimento ou paralisias. A vida cultural e a possibilidade do uso de símbolos caracterizam o ser humano. Simbolizar é integrar e a vivência de integração também pode desconcertar.

Marcio traz o filósofo Agambem (2008) para nos ajudar a pensar essas questões e o poeta Ossip Mandelstam. Fui pesquisar um pouco (Internet) mais sobre ambos e encontrei algo bastante interessante sobre o escuro. Se referem ao contemporâneo como algo singular ao tempo quando aderimos a ele e dele nos afastamos, pois, a aderência total paralisa e nos impede de enxergar e pensar. O escuro aparece aqui nesta dialética, e perceber no escuro do presente uma luz que procura nos alcançar, mas não pode fazêlo, isso é ser contemporâneo. Isso é estar num estado de desconcerto. Perceber o escuro não é passividade, é poder neutralizar as luzes e enxergar as trevas, é não ficar fixado numa luz de estrelas que já não existem mais. É saber que há luzes que ainda não nos alcançaram. $\mathrm{O}$ ato de fé é inerente à escuta. Essa luz do passado também nos indica o caminho das identificações e desidentificações no processo de busca de ser si mesmo. O escuro não é ausência de luz ou uma não visão, do ponto de vista fisiológico, mas uma atividade especial da retina. Esta se adapta de forma específica para poder ver o escuro.

Desarmonia, desconcerto pode lançar o ser humano no caos, na loucura ou no uso da capacidade criativa. Formas de viver cesuras.

Marcio faz uma relação de alguns tipos de cesura. $\mathrm{O}$ autor afirma que a individualidade não ocorre fora da experiência de pânico. Mas não seria o pânico um sinal de que a subjetividade não teve lugar? Podemos considerar que nosso momento histórico gera sofrimento onde a individualidade e a singularidade não têm lugar? Num concerto 
musical, diz ele, de repente, pode surgir um grito de fogo que desestrutura, instaurando pânico e a individualidade irrompe. Penso que este modelo traz em si a ideia de catástrofe. Mas, pergunto se a individualidade só surge a partir do pânico. Quando assistimos a um concerto musical, temos músicas agradáveis e desagradáveis, harmônicas e desarmônicas, pacificadoras e inquietantes, tal como numa sessão de análise. Mas, no concerto musical em si, na experiência estética o surgimento da subjetividade acontece. A psicanálise provocou uma fratura no pensamento ocidental. E penso que continua provocando. Depois de Freud, muitas teorias vêm surgindo para tentar explicar e atender as necessidades do ser humano. Seguidores de Freud, formam uma cacofonia, afirma o autor, ruído confuso que dificulta o diálogo; fanatismo das escolas é esterilizante, virando uma letra morta. Assim, há conceitos já mortos que impedem a visão da obscuridade, outros que podem iluminar e outros, ainda, podem ganhar novas amplitudes. Quanto a isto, penso que o analista é quem contribui para o avanço ou retrocesso da psicanálise, com sua postura de abertura. Ao invés de cacofonia, podemos ter ouvidos para a polifonia e termos assim vários instrumentos como numa orquestra. Podem ocorrer sons estranhos, ou silêncios ou vazios nessas polifonias e o analista precisa viver essas situações que podem gerar inquietação. Como usamos nossas teorias? É possível o diálogo? Penso que sim. Diálogo não é concordância total. Vários pontos de vistas e mudanças na qualidade de sofrimentos humanos vem ocorrendo. Por exemplo, Winnicott (1971/1975) faz uma mudança de perspectiva em sua investigação, afirmando que o ser humano não é só pulsionalidade, propondo ampliar a compreensão para questões relacionadas ao ser, a conquista do sentir-se real na vida onde a pulsionalidade é um dos fatores e é uma conquista na vida do bebê. O ser não se forma sem o outro.

O campo da irrepresentabilidade tem sido bastante considerado na psicanálise. Penso que a ideia de desconcerto inclui essa dimensão onde fica-se sem o símbolo de imediato. No conceito de inconsciente que alguns autores tentam expandir a partir do que já foi descoberto, como Winnicott (1974/2005). Este autor, quando se refere ao medo do colapso, introduz um conceito de inconsciente que não é o inconsciente reprimido de Freud, mas que diz respeito a vivências ocorridas que não foram experimentadas, quando não havia um ego capaz de coloca-las sob seu domínio onipotente. Será que podemos pensar que as experiências de invasões externas e 
internas provocam o sentimento de desconcerto? Do irrepresentável? As fraturas são geralmente desconcertantes? Márcio vai avançando em seu pensamento, trazendo a questão da mídia, do ser informacional da contemporaneidade, falando do conceito de Édipo a ser expandido e pensar que termos novos surgem. O modelo de família já não nos serve, é insuficiente? A compreensão do ser humano requer novos modelos? A importância da história, cultura, política vem sendo relevada no nosso viver e pensar. Tudo isso está presente na clínica. Luciano Floridi (2017), professor de filosofia da informação, é citado por Marcio, falando de quatro revoluções na compreensão do eu e do mundo. 1. Copérnico; 2. Darwin; 3; e 4. Alan Turing, matemático britânico, pioneiro da computação, que afirma que os humanos são organismos informacionais conectados na infosfera. Os termos on line e off line já não fazem sentido, como se dentro e fora perdessem seu significado, e usa o termo on life com consequências ainda imprevisíveis na estruturação da identidade. A vida tecnológica cabe no conceito de espaço potencial? Penso que este item é fundamental para nós. Como se constitui a identidade e a subjetividade na contemporaneidade? A vida digital exerce influência na formação do self? Quais as necessidades básicas do ser humano? Empatia, receptividade, ter um lugar, ser si mesmo. Ser encontrado e reconhecido. Ser é conhecer-se. Nossa escuridão hoje, parece dizer respeito a essa questão. A experiência clínica é nossa guia nesta escuridão, como sempre foi na história, mudando e ampliando o método psicanalítico. A psicanálise vem se desenvolvendo e temos teorias novas iluminando experiências mais primitivas do ser humano. As vivências primitivas até agora consideradas a partir das observações clinicas se modificam? Para isso precisamos escutar. E a questão da escuta é fundamental para que sejamos hospitaleiros com o outro.

A surpresa e perplexidade são iluminadores das obscuridades nestas travessias do processo analítico e são inerentes à escuta. O analista é um investigador. E como tal, Mariano nos apresenta os três modelos de detetives.

Enigma, mistério, desconcerto. No texto é citado um exemplo, o método morelliano..Giovanni Morelli(1816-1891) foi um historiador italiano da arte e tinha função de descobrir quando um quadro era falso e copiado. Para isso fazia uma investigação de detalhes aparentemente insignificantes para descobrir onde o pintor se 
descuidava. Modelo dos atos falhos. O mistério é exemplificado com Schliemann (1822-1890), arqueólogo alemão que queria descobrir o lugar onde estava a cidade de Troia e tudo fez para isso, acreditando que estava no caminho certo com os achados que ia fazendo. Depois viu que se enganou e que estava fazendo uma descoberta, mas não Troia e sim uma cidade outra de 1250 anos atrás. São possibilidades da investigação diante de enigma e mistério. As escutas do analista contem essas diferenças as vezes, sutis. Ora de forma objetiva, ora de forma mais subjetiva. Ora como decifrador, ora como aquele que se inclui para entrar no campo da subjetividade do outro para trabalhar na clínica dos borders. Penso que a história da técnica psicanalítica se revela nessas ilustrações.

O autor se refere ao modelo do segredo relacionando-o com as perversões. O segredo é o que oculta, e com ele estamos no campo da espionagem. Aqui estamos no campo da perversão onde a escuta é invasora e violenta se assemelhando a um voyeurismo, reeditando a cena primária.

Mas será que o segredo só pode ser visto desta maneira? Não faz parte do desenvolvimento psíquico a criança descobrir que pode guardar segredos? E este expressar a descoberta e criação de fronteiras entre o interno e o externo, on e off? Qual o tipo de escuta para não invadir o paciente? A exposição maciça na contemporaneidade impede a invisibilidade necessária para alguma privacidade, importante para estruturação da subjetividade? Como lidamos com isso? Questões a serem pensadas. Qual a visão antropológica do ser humano, de cada autor?

A terceira forma detetivesca faz analogia com os poetas. Roberto Bolaño (2006) em seu livro Os detetives selvagens, nos dá um modelo de analista como detetive selvagem e é aqui que o desconcerto encontra seu lugar. $\mathrm{O}$ analista converte seu desconcerto em exercício desconcertante e ao mesmo tempo, oferece refúgio e espaço de construção, respostas provisórias. $\mathrm{Na}$ contemporaneidade, a liquidez substitui a solidez. Que mudanças são necessárias para que o método e setting psicanalíticos possam alcançar essas formas de viver? A tecnologia tende a desfazer tempo e espaço, penso que é isso a 
liquidez, ou criar alguma dimensão onde quase não há espera, se é que isso é possível. É a ilusão que mantém o ser humano em estado de indiferenciação. Estará este buscando uma regressão no progresso? As calamidades humanas que assistimos poderiam ser compreendidas como desesperanças e vazios de ser si mesmo? Ser humano é só constituído pela pulsionalidade? As questões da identidade e subjetividade não abarcariam questões relacionadas à formação do ser? Quais as questões éticas presentes?

Desconcertar é desmontar, analisar. Esta é a função analítica. Dentro da dialética podem ocorrer concertos férteis e estéreis e desconcertos férteis e estéreis. Precisaríamos sofisticar o que cada um destes pode significar.

Os desafios estão sempre presentes na clínica psicanalítica. Vemos o mundo convulsionar em vários momentos e isto influencia na constituição da subjetividade. Mas as convulsões sempre existiram na história da humanidade. Os pacientes, hoje, são diferentes de tempos atrás? Sim e não, muitas vezes, no consultório, assistimos dramas emocionais que não dizem respeito ao tempo cronológico e às mudanças sociais, políticas. Por vezes, nos reencontramos com funcionamento histérico, neuróticos, psicóticos, borderlines e outros sintomas como produtos singulares da história de vida do analisando. A história de cada um, a cultura tem símbolos singulares e precisamos ouvir o idioma pessoal do paciente. As questões da violência, da maldade humana ainda causam espanto. Mas, também causam fascínio em sua capacidade criativa. A fera (terror) e a beleza surpreendem. Para tolerar a surpresa, o assombro, um mínimo de maturidade psíquica é necessário, mas nem sempre suportamos, e a postura do analista é fundamental. E o analisando vai no seu processo analítico, desenvolvendo essa capacidade no próprio exercício da psicanálise. O processo de desilusão com segurança e confiança pode ajudá-lo. Por isso, importante que Mariano não esquece de valorizar os momentos de concertos na análise, nos tempos convulsionados onde a segurança e sustentação com continuidade são importantes. Momentos de sem lei desorientadores fazem com que a análise possa ser vivida como refúgio e espaço familiar. Em certos estados psíquicos muito primitivos as perguntas e interpretações não cabem. A análise assim, pode converter-se em guia dos perplexos. Ser um estrangeiro. Não é isso 
conquista da alteridade? Como afirma Moguillansky, R.(2004), "perplexidade é um tipo de emoção que se origina ante algo que não entendemos, não compreendemos, não podemos representar, e no entanto, admitimos como existente, pensável. Pensável é, se acrescentamos o que se adiciona à perplexidade, pensar o que podemos representar e também pensar o que não podemos representar". (pg. 238) E continua: "Resgatar a capacidade de pensar por parte do analista, daquilo que por diferentes razões não pode representar, tem enorme transcendência na marcha de uma análise; quando o analista considera o não representável existente, pensável, dá condições de possibilidade a transformações em seu paciente naquilo que faltou de representação". O analista está implicado no processo analítico.

No caso clínico que Marcio apresenta, podemos ver com clareza essas questões aparecendo. Na experiência de Afonso, um homem sem lugar e em estado de solidão, num determinado momento, surge um pânico, com o qual se assusta e sente que tudo desmoronou e acabou. O analista oferece outra visão a ele, oposta, mostrando a evolução, a mudança ocorrendo. Dar uma representação ao que não tinha representação, propiciando o surgimento de sua subjetividade. O paciente pode ouvir e se tranquilizar no seu desespero e conceber algo novo; mudança não é ausência de angústia e dor, pelo contrário. As novas alternativas que surgem a ele e a qualquer analisando ou qualquer pessoa na vida, sempre geram tensão pois abrem novas possibilidades de desconcerto. $\mathrm{E}$ de conhecimento. Na presença viva do analista humano.

Para terminar, li uma poesia que penso expressa essa infinitude e desconcerto do processo do conhecimento. É de Wislawa Szymborska (1923-2012), poeta polonesa(Wikipedia). A poesia é sobre o número, em matemática, PI, o número do mistério sobre o qual não se conhece nunca a última casa decimal, considero o número do desconcerto:

\section{Pi}

O admirável número pi:

três vírgula um quatro um. 
Todos os dígitos seguintes são apenas o começo, cinco nove dois porque ele nunca termina. Não se pode capturá-lo seis cinco três cinco com um olhar, oito nove com o cálculo, sete nove ou com a imaginação, nem mesmo três dois três oito comparando-o de brincadeira quatro seis com qualquer outra coisa dois seis quatro três deste mundo.

A cobra mais comprida do planeta se estende por alguns metros e acaba.

Também são assim, embora mais longas, as serpentes das fábulas.

O cortejo de algarismos do número pi

alcança o final da página e não se detém.

Avança, percorre a mesa, o ar, marcha

sobre o muro, uma folha, um ninho de pássaro, nuvens, e chega ao céu, até perder-se na insondável imensidão.

A cauda do cometa é minúscula como a de um rato!

Como é frágil um raio de estrela, que se curva em qualquer espaço!

E aqui dois três quinze trezentos dezenove meu número de telefone o número de tua camisa o ano mil novecentos e setenta e três sexto andar o número de habitantes sessenta e cinco centavos a medida da cintura dois dedos uma charada um código, no qual voa e canta descuidado um sabiá!

Por favor, mantenham-se calmos, senhoras e senhores, céus e terra passarão mas não o número pi, nunca, jamais.

Ele continua com seu extraordinário cinco, seu refinado oito, seu nunca derradeiro sete, empurrando, arf, sempre empurrando a preguiçosa eternidade.

\section{Referências}

Agamben, G.(2008).- Che cos"è il contemporâneo? Nottetempo

Bolaño, R. (2006). Os detetives selvagens. S.Paulo: Companhia das Letras

Floridi, Luciano (2017). La quarta rivoluzione. Raffaello Cortina Editore. Milano

Winnicott, D. W. (1971/1975). O brincar e a realidade. Rio de Janeiro: Imago

Winnicott, D. W. (1974/2005). O medo do colapso. In Explorações psicanalíticas. Porto Alegre: Artmed. 
Moguillansky(2004) Nostalgia del absoluto, extrañeza y perplejidad; Buenos Aires: ed. Libros del Zorzal 